\title{
Saliva: an important alternative for screening and monitoring of COVID-19 in children
}

\section{Catielma Nascimento SANTOS ${ }^{(a)}$ \\ Karla Mayra REZENDE(a) (D) Nilson Ferreira de OLIVEIRA NETO(b) \\ Thelma Suely OKAY(c) \\ Paulo Henrique BRAZ-SILVA(d) (D) \\ Marcelo BÖNECKER ${ }^{(a)}$}

(a) Universidade de São Paulo - USP, School of Dentistry, Department of Pediatric Dentistry and Orthodontics, São Paulo, SP, Brazil.

(b) Universidade Federal de Uberlândia - UFU, School of Dentistry, Department of Pediatric Dentistry, Uberlândia, MG, Brazil.

(c) Universidade de São Paulo - USP, School of Medicine, Institute of Tropical Medicine of São Paulo and Department of Pediatrics, São Paulo, SP, Brazil.

(d) Universidade de São Paulo - USP, School of Dentistry, Department of Stomatology, São Paulo, SP, Brazil.

Declaration of Interests: The authors certify that they have no commercial or associative interest that represents a conflict of interest in connection with the manuscript.

Corresponding Author:

Paulo Henrique Braz-Silva

E-mail:pbraz@usp.br

htrps://doi.org/10.1590/1807-3107bor-2020.vol34.0125

Submitted: September 9, 2020

Accepted for publication: October 29, 2020

Last revision: October 30, 2020
Abstract: The increasing number of cases of COVID-19 worldwide poses challenges to healthcare systems not only in effectively identifying individuals positive for SARS-CoV-2, but also in isolating cases to minimise contagion in early diagnosing more severe cases that will need hospitalization. Less-invasive collection methods are indispensable in a pandemic scenario as large-scale tests are necessary to understand the actual evolution of contagion in different populations, thus enabling decision-making based on scientific evidence. Saliva has been shown to be an alternative for diagnosing viral infections as this biological fluid can be easily and quickly collected without using specific devices and causing less discomfort during collection, which is an important factor for use in children. Despite the smaller percentage of severe cases of COVID-19 among children, they seem to play an important role in the contagion as they have the same potential of transmission as that of adults. Knowing the evolution of COVID-19 pandemic in children is extremely important, mainly regarding the changing in rules of social distancing, such as re-opening schools and recreational activities spaces. In addition, countless cases of a severe multi-systemic inflammatory syndrome that shares clinical and laboratory features with Kawasaki's disease have been recently related to SARS-CoV-2 infections in children, adolescents and young adults. In view of this scenario, the aim of this study was to present saliva as an alternative for seeking diagnostic and prognostic markers of COVID-19 in children, including adequate sample collection techniques for different age groups.

Keywords: Coronavirus; COVID-19; Diagnosis; Pediatrics; Saliva.

\section{Introduction}

An epidemic of the new coronavirus started in the city of Wuhan, Hubei Province, China, in early December 2019.1 The coronavirus-associated disease (COVID-19) is caused by the severe acute respiratory syndrome coronavirus 2 (SARS-CoV-2) that spread very quickly worldwide, so that COVID-19 was declared a pandemic by the World Health Organization (WHO) in March, 2020. Coronaviruses are known to be pathogenic to both, animals and humans, and are related to gastrointestinal and respiratory symptoms. ${ }^{2}$ 
The disease may be symptomatic or asyntomatic. ${ }^{3}$ The children appear to have milder symptoms than adults. ${ }^{4}$ However, the course of the disease is worse and can lead to death, especially in risk groups such as the elderly and individuals with hypertension, diabetes, obesity, chronic respiratory and cardiovascular diseases. ${ }^{5}$ However, there are a few cases reporting children who died due to COVID-19. ${ }^{6}$

Over time and the pandemic spreading to different countries and continents, the number of cases of COVID-19 among children is increasing and the cases of Kawasaki's-like disease have also been more frequently reported. ${ }^{7}$ The role of children in the COVID-19 transmission remains unclear, but there are no reports indicating that children have less potential of dissemination than adults. ${ }^{8,9}$ That is why diagnostic testing in this group is so relevant, particularly regarding the re-opening of kindergartens and schools as children have a poorer understanding of biosecurity measures.

Nasopharyngeal, oropharyngeal and relatednasopharyngeal aspiration techniques may be used for diagnosing the new coronavirus. In hospitalized patients, lower respiratory tract specimens such as sputum, broncho-alveolar or tracheal lavage and aspirates can be used to perform the gold standard diagnostic technique, the Real Time Reverse-Transcription Polymerase Chain Reaction (RT-PCR). ${ }^{8}$ Aside for the high cost of reagents and dedicated equipment, the collection and processing of samples are time consuming and require specialized handlers to perform the sample collection through the insertion of swabs at the deepest point of the oropharynx and nasopharynx, frequently causing discomfort and retching, especially in children. As a good alternative, saliva has been shown to be an effective biological sample for carrying out viral detection methods ${ }^{9}$ and a less traumatic/invasive procedure for pediatric patients. ${ }^{10}$

As the pandemic progresses towards the stabilization in some countries, there is an imminent need to re-open kindergartens, schools, as well as recreational spaces for children. However, less complex collection methods for the identification of SARS-CoV-2 are necessary, mainly through large-scale testing, in the case of children in schools. Saliva is a good biological fluid because it enables the identification of different viruses, as has already been shown in other infectious models. ${ }^{10}$ Furthermore, saliva can be quickly and conveniently collected by using cheap and non-invasive methods. ${ }^{10}$ For younger children, who seem to be one of the target audiences in the context of saliva sampling instead of respiratory secretions, a saliva test is a much more attractive and less invasive form of collection, and this paper describes a number of saliva collection techniques for children in different age groups. There is no specific information in the literature on the types of test and how to perform salivary for the diagnosis of COVID-19. Therefore, the aim of this study was to review the literature on the possibilities to diagnose COVID-19 in children by means of saliva sampling and analyses and to describe appropriate collection techniques for different age groups.

\section{Symptomatology of COVID-19 in childhood}

There are a few studies on COVID-19 in children. When compared to infected adults, the number of cases is lower in children, symptoms are considered milder, the mortality rate is lower ${ }^{11,12}$ and the prognosis is more favorable. ${ }^{3,13}$ It has been shown that in infants and young children, the disease is relatively more severe than in older children and adolescents. ${ }^{14}$

At the present time, the contamination in this group occurs through contact with infected adults, as children's environments such as schools, kindergartens and playgrounds remain closed. ${ }^{8}$ There is a low probability of transmission to neonates whose mothers are diagnosed with COVID-19 at delivery, provided that breastfeeding is performed with the recommended precaution measures, such as the correct washing of hands and use of face mask by the mother. ${ }^{3}$

The incubation period in children is generally of two days, but can vary from 2 to 10 days. ${ }^{6}$ The clinical classification and characteristics of the novel coronavirus infections are described in Table 1. Although symptomatic cases usually attract more attention, asymptomatic children should be closed monitored as they can play a significant role in 
the transmission of SARS-CoV-2 infections. ${ }^{15}$ Asymptomatic infected children are defined as those who do not have any clinical signs and symptoms or imaging findings of the disease such as the ground glass patching opacities in the thorax tomography, but tested positive for COVID-19 by RT-PCR or a serological method. ${ }^{3}$

On the other hand, symptomatic infected children may have fever, dry cough, fatigue, upper airway respiratory symptoms (e.g. nasal congestion and runny nose) and gastrointestinal symptoms (e.g. abdominal discomfort, nausea, vomiting, abdominal pain and diarrhea). ${ }^{15,16}$

Although the literature shows that there are several cases of mildly affected children, SARS-CoV-2 may cause a severe multi-systemic hyper-inflammatory reaction in genetically predisposed children, described as a Kawasaki's disease. This condition is likely to have a viral etiology and myocardial cell tropism, causing myocarditis and affecting the coronary arteries. ${ }^{17}$ The diagnosis criteria for Kawasaki's disease is the presence of fever for five days with at least four out of five clinical criteria, in the absence of an alternative diagnosis. ${ }^{8}$

Jones et al., ${ }^{8}$ were among the first authors who reported a case of a 6-month-old infant with COVID-19 infection and Kawasaki's disease. According to them, the child presented with fever, restlessness, refusal to eat, irritability, limbic sparing conjunctivitis, dry cracked lips, and the presence of an erythematous, apparently non-pruritic, blotchy cutaneous rash, mild sub-costal retractions suggestive of a respiratory distress and faint opacities were observed in the middle area of the left lung on the chest radiography. The echocardiogram was normal.

As far as we are concerned, there is not yet a guideline especially devoted to children with COVID-19 and comorbidities, such as chronic respiratory diseases, immune suppression conditions, uncorrected heart disease and chronic kidney disease. This population needs better surveillance, early diagnosis and supportive treatment. ${ }^{14}$

\section{Re-opening of schools and saliva as a diagnostic fluid}

Due to the COVID-19 pandemic, kindergartens and schools were closed in an attempt to restrain the dissemination of the virus among children, the school staff, and their families. This measure has been discussed by UNESCO together with UNICEF and WHO. In general, the closure of schools causes a negative impact on child learning ${ }^{18}$ besides puts additional economic and psychological stress on families. ${ }^{19}$

Table 1. Clinical classifications of the characteristics of the 2019 novel coronavirus infections in children according to an expert consensus statement. ${ }^{15}$

\begin{tabular}{ll}
\hline Clinical classifications & \multicolumn{1}{c}{ Characteristics } \\
\hline Asymptomatic infection & $\begin{array}{l}\text { Children tested positive for 2019-nCoV, but without clinical manifestations or abnormal chest imaging } \\
\text { findings. }\end{array}$ \\
$\begin{array}{l}\text { Acute upper respiratory tract } \\
\text { infection }\end{array}$ & $\begin{array}{l}\text { Children presenting with fever, cough, pharyngeal pain, nasal congestion, fatigue, headache, myalgia } \\
\text { among other signs and symptoms, but without signs of pneumonia according to the chest imaging or sepsis. } \\
\text { Children with or without fever, respiratory symptoms such as cough; and chest imaging indicating } \\
\text { pneumonia, but not reaching the criteria of severe pneumonia. }\end{array}$ \\
& $\begin{array}{l}\text { 1. Increased respiratory rate: } \geq 70 \text { times/min ( }<1 \text { year), } \geq 50 \text { times/min ( } \geq \text { lyear) (after ruling out the } \\
\text { effects of fever and crying); }\end{array}$ \\
2. Oxygen saturation; & $\begin{array}{l}\text { 3. Hypoxia: assisted breathing (moans, nasal flaring, and three concave signs), cyanosis, intermittent apnea; } \\
\text { Severe pneumonia }\end{array}$ \\
4. Disturbance of consciousness: somnolence, coma or seizures; \\
5. Food refusal or feeding difficulty, with signs of dehydration. \\
Those who meet any of the following criteria and require ICU admission: (1) Respiratory failure requiring \\
mechanical ventilation; (2) Shock; (3) Combined with other organs failure.
\end{tabular}


However, the re-opening of schools should only take place after ensuring that all students and school employees are safe, ${ }^{20}$ which is consist with the sanitation measures taken by each country. ${ }^{18}$ It is known that, in view of the current circumstances, children may be at real risk of contracting COVID-19 infection regardless of their age. ${ }^{88}$ According to Viner et al., ${ }^{21}$ children and adolescents aged between 10 and 19 years old can be as vulnerable to the new coronavirus infection as adults. Another study showed that the replication of SARS-CoV-2 in older children led the viral load to levels similar to those found in adults, whereas significantly higher amounts are detected in children younger than 5 years old. ${ }^{20}$ Because all these age groups correspond to the school-age population, the return to school could lead to new outbreaks of the disease as children and adolescents may not respect the safety measures, thus increasing the risk of contamination.

There are some protocols being used in commercial places for restraining the dissemination of the virus, namely: cleaning the shoes before entering the building, measuring the body temperature, wearing face mask mandatorily, washing hands with soap or rubbing them with $70 \%$ alcohol, and keeping social distancing of about 1.5 meter from another person. ${ }^{19,22}$

The document entitled "Considerations for school-related public health measures in the context of COVID-19", developed with input from the Technical Advisory Group (TAG) of Experts on Educational Institutions and COVID-19 and experts from WHO, UNICEF, and UNESCO, reports some more specific indications for school operations in the context of COVID-19. ${ }^{23}$ Table 2 shows the summarised information of this document. ${ }^{23}$ This guidance is relevant for children, parents or caregivers, teachers and other staff, besides having an impact on the general society.

Thus, thinking about the function and importance of schools for the intellectual and social development of children, the re-opening must be done safely. For this reason, large-scale testing using saliva ${ }^{24}$ can be a viable alternative to ensure testing of all children and school staff before and during the re-opening of the schools. Hence, depending on the child's age and level of understanding about the pandemic, complying with safety rules can be complicated. In addition, the suspicion of positive COVID-19 can be more difficult, especially when they are asymptomatic, making it difficult to screen for SARS-CoV-2.

\section{Saliva-based diagnosis and screening of COVID-19 in children}

Many studies report that blood has a direct relationship with saliva due to the existence of cellular and molecular bonds between these fluids. ${ }^{25}$ It is suggested that both salivary IgG and IgM are derived from blood. Saliva is a mixture of secretions of different salivary glands, desquamated oral epithelia, gingival crevicular fluid and several microorganisms. It also contains a large number of proteins, such as immunoglobulins, in particular of secreted IgA, mucins, and enzymes, as well as metabolites, hormones, and electrolytes. ${ }^{26}$ This composition allows the detection of pathogens in saliva and also the quantification of biomarkers that can provide information on the immunological, inflammatory, endocrine, and metabolic status of each individual. . $7,28,29,30$

Viral infections can be diagnosed in the saliva by directly targeting the genetic material of the virus (i.e. DNA or RNA) or indirectly, by searching for signatures left by these infections, such as proteins (proteomic analysis), metabolites (metabolomic analysis), miRNAs and other transcriptomic analyses and immunoglobulin profiles (IgA, $\operatorname{IgG}$ and $\operatorname{IgM}){ }^{31}$

Immunoglobulins such as IgM, IgG and IgA, the latter abundant in saliva, can act as biomarkers in the saliva, allowing this fluid to be used for diagnosing and monitoring of these infections. ${ }^{32}$ In addition, they also enable the development of point-of-care diagnostic devices, which are extremely useful for mass application. ${ }^{33}$

SARS-CoV-2 has been found in saliva on a sustained basis. ${ }^{34}$ The viral particles found in the oral cavity can come from different sources, such as the upper respiratory tract, crevicular gingival fluid and/or come directly from the salivary glands. ${ }^{35}$

In fact, asymptomatic individuals do not present with a typical respiratory pattern despite the 
Table 2. Summary of considerations for school-related public health measures in context of COVID-19. ${ }^{23}$

\begin{tabular}{|c|c|}
\hline Orientations & Detailing \\
\hline \multirow{6}{*}{ Physical distancing } & Maintain a distance of at least 1 metre for both students (all age-groups) and staff, where feasible. \\
\hline & Limit mixing of classes and of age groups for school and after-school activities. \\
\hline & $\begin{array}{l}\text { The high-school timetable can be modified, with some students and teachers attending in the morning, } \\
\text { others in the afternoon, others in the evening. Schools can also minimize shared break times by alternating } \\
\text { when and where classes take meals. }\end{array}$ \\
\hline & $\begin{array}{c}\text { Consider increasing the number of teachers or having recourse to volunteer support, if possible, to allow for } \\
\text { fewer students per classroom (if space is available). }\end{array}$ \\
\hline & $\begin{array}{c}\text { Ensure crowd control during school or day-care drop off and pick up periods; clearly identify entry and exits, } \\
\text { with marking direction for walking; consider restrictions for parents and care-givers entering school campus } \\
\text { and premises. }\end{array}$ \\
\hline & $\begin{array}{c}\text { Create awareness that ensures students do not gather in large groups or in close proximity when in lines, } \\
\text { when leaving the school and in their free time. }\end{array}$ \\
\hline \multirow{4}{*}{ Wearing of masks } & Children aged 5 years and under should not be required to wear masks. \\
\hline & $\begin{array}{c}\text { For children between six and } 11 \text { years of age, a risk-based approach should be applied to the decision to } \\
\text { use a mask. }\end{array}$ \\
\hline & Children and adolescents 12 years or older should follow the national mask guidelines for adults. \\
\hline & All efforts should be made to ensure the use of a mask does not interfere with learning. \\
\hline \multirow{6}{*}{ Ventilation } & Consider using natural ventilation. \\
\hline & Ensure adequate ventilation, mainly to occupied spaces. \\
\hline & $\begin{array}{l}\text { If heating, ventilation and air conditioning (HVAC) systems are used, they should be regularly inspected, } \\
\text { maintained and cleaned. }\end{array}$ \\
\hline & $\begin{array}{l}\text { For mechanical systems increase the total airflow supply and the percentage of outdoor air, such as by using } \\
\text { economizer modes of HVAC operations (potentially as high as } 100 \%) . \mathrm{C} 17\end{array}$ \\
\hline & Disable demand-control ventilation (DCV) controls that reduce air supply based on temperature or occupancy. \\
\hline & $\begin{array}{c}\text { Consider running the HVAC system at maximum outside airflow for } 2 \text { hours before and after times when the } \\
\text { building is occupied. }\end{array}$ \\
\hline \multirow{4}{*}{ Hygiene and daily practices } & Create a schedule for frequent hand hygiene. \\
\hline & $\begin{array}{c}\text { Provide sufficient soap and clean water or alcohol-based rub at school entrances and throughout the school } \\
\text { and in classrooms. }\end{array}$ \\
\hline & $\begin{array}{l}\text { Schedule regular cleaning of the school environment as well as daily increase frequency of cleaning in the } \\
\text { canteen, gym and sports facilities and changing rooms. }\end{array}$ \\
\hline & $\begin{array}{c}\text { Put in place respiratory and hand hygiene and physical distancing measures in transportation such as } \\
\text { school buses. }\end{array}$ \\
\hline \multirow{3}{*}{$\begin{array}{l}\text { Screening and management } \\
\text { of sick students, teachers and } \\
\text { other school staff }\end{array}$} & $\begin{array}{c}\text { Enforce the policy of "staying at home if unwell" for students, teachers or school staff with potential } \\
\text { COVID-19 infection and connect them with local healthcare providers for assessment, testing and care. } \\
\text { If possible, connect with local organizations to provide home care support and ensure communication } \\
\text { between home and school. }\end{array}$ \\
\hline & $\begin{array}{c}\text { Consider daily screening for history of fever or feeling feverish in the previous } 24 \text { hours upon entry into the } \\
\text { building for all staff, students and visitors to identify persons who are sick. }\end{array}$ \\
\hline & $\begin{array}{l}\text { Ensure students who have been in contact with a COVID-19 case stay home for } 14 \text { days. School officials } \\
\text { should notify public health authorities in the event of a positive COVID-19 case among students or staff. }\end{array}$ \\
\hline
\end{tabular}

presence of viable virus particles in their oral fluids. ${ }^{36}$ In this sense, in the context of other infectious diseases, some studies have shown that it is possible to detect the presence of different viruses in saliva samples. ${ }^{35,37,38}$

Saliva collection is a simpler and cheaper procedure, in addition to being better tolerated by children and their parents, which makes this method even more attractive for the pediatrician as it is a minimally invasive approach. ${ }^{39}$ Another advantage of this collection method is that it can be safely performed by the children's parents, which significantly reduces the costs of COVID-19 testing, as no specialised professional is needed for the sample collection, 
and consequently, there is no risk of exposure for the healthcare team. ${ }^{40}$

\section{Saliva collection techniques for children}

There is a great variety of saliva collection methods, such as aspiration with syringe and test tube, open or closed suction, expectoration or spit, drainage and swab. The choice of the method for children should be made according to their age and degree of understanding (Table 3). ${ }^{41}$

To perform the salivary tests, it is not necessary to perform tooth brushing or make a mouthwash. ${ }^{42}$ As the diagnosis is also for virus, this type of test can be made at any moment of the day. An important aspect to be considered is that the amount of saliva to be collected should be around $3 \mathrm{~mL}$, which can be accomplished with or without stimulation. In case of saliva production after stimulation, the collection procedure can be performed mechanically (e.g. chewing gum, paraffin, latex) or chemically (e.g. citric acid at $1-5 \%){ }^{43}$ Irrespective of the collection method chosen, it is a challenge to collect enough saliva from neonates and infants up to 3 months of life, as this group of children in general produce very little saliva ${ }^{44}$ In the literature, it is recommended to drip some drops of $5 \%$ citric acid onto the sub-lingual floor in order to stimulate an increased production of saliva, ${ }^{45}$ which will therefore be aspirated with syringe and test tube. ${ }^{46}$

In children older than 6 months, the salivary glands in the oral cavity region begin to produce saliva spontaneously and regularly, which certainly make its collection easier. This can be carried out in two ways, namely, by aspirating the saliva with syringe and test tube or by using the open suction technique. ${ }^{47}$

In the open suction technique, the saliva is aspirated through a plastic tube, which is connected to a portable suction machine, into a container where it will be collected and stored. For this type of collection, the child should be encouraged to keep the mouth open for 15 seconds, on average, at intervals of two minutes. ${ }^{47}$ There is also the closed suction technique, in which a saliva collection tube is placed below the tongue and the child is asked to keep the lips closed around it for two minutes. ${ }^{47}$ However, this technique is indicated only for children older than 3 years.

For children older than 6 years, saliva can be collected by using the expectoration or spit method, in which the child should keep the mouth closed for three minutes without swallowing so that the saliva is accumulated and then spit into the collection tube. ${ }^{47}$ However, because this technique may be difficult to perform in some children due to their difficulty in not swallowing the saliva for a given period of time, the drainage technique can be a viable alternative. In the drainage technique, the child is initially asked to swallow the saliva, so that new amounts of saliva are produced before being drained through the half-opened lips and directly stored into the collection tube.

The swab method can also be used as an alternative for collecting saliva. For doing so, three cotton rolls are placed in different sites of the oral cavity: one below the tongue in order to absorb the saliva close to the excretory duct orifices of the sub-mandibular

Table 3. Summary of the saliva collection techniques according to the children's age group.

\begin{tabular}{|c|c|c|c|c|}
\hline \multirow[b]{2}{*}{ Techniques } & \multicolumn{4}{|c|}{ Age } \\
\hline & $0-6$ months old & $\begin{array}{l}\text { Early childhood (up } \\
\text { to } 3 \text { yrs) }\end{array}$ & $\begin{array}{c}\text { Pre-school age (3- } \\
6 \text { yrs) }\end{array}$ & $\begin{array}{c}\text { School age ( } \\
\text { yrs) }\end{array}$ \\
\hline Aspiration of saliva with syringe and test tube & $x$ & $x$ & & \\
\hline Open suction & & $x$ & $x$ & $x$ \\
\hline Close suction & & & $x$ & $x$ \\
\hline Expectoration or spit & & & & $x$ \\
\hline Drainage & & & & $x$ \\
\hline Swab & & $x$ & $x$ & $x$ \\
\hline
\end{tabular}


and sub-lingual glands, and the other two cotton rolls close to the excretory ducts orifices of the parotid glands, one on each side of the oral cavity. The cotton rolls should remain inside the child's oral cavity for 2-3 minutes, on average, so that they are soaked with saliva. At the end of the saliva collection, the cotton rolls are removed and placed into a test tube before being properly closed. The recovery of the absorbed saliva occurs by means of centrifugation of the test tube containing the cotton rolls inside, ${ }^{48}$ which results in a sample of clear fluid. This technique requires no cold storage, a condition that is frequently used in other methods for saliva collection. . $^{4,49,50}$

\section{Conclusion}

COVID-19 symptomatic and asymptomatic patients can be diagnosed by means of saliva, whose advantage is to be less invasive, simpler, cheaper and relatively quickly sampled. In addition, the risk of dissemination for healthcare professional is reduced as the saliva can be collected by the own individual or the children's parents. Another important advantage of saliva is that it can be serially collected, which is a key factor in a dynamic infection context, as is the case of COVID-19. Another point to be highlighted is that saliva is an excellent fluid to detect not only the virus genetic material, but also signatures of previous infections by using proteins (proteomic), metabolites (metabolomic), micro RNAs and transcriptomic and immunoglobulins, mainly IgA analyses.

In view of this, saliva can be considered an alternative biological fluid for screening and diagnosing COVID-19 in children, thus playing a key role in the understanding of the behaviour of the infection in childhood.

\section{References}

1. Chan JF, Yuan S, Kok KH, To KK, Chu H, Yang J, et al. A familial cluster of pneumonia associated with the 2019 novel coronavirus indicating person-to-person transmission: a study of a family cluster. Lancet. 2020 Feb;395(10223):514-23. https://doi.org/10.1016/S0140-6736(20)30154-9

2. Salata C, Calistri A, Parolin C, Palù G. Coronaviruses: a paradigm of new emerging zoonotic diseases. Pathog Dis. 2019 Dec;77(9):77. https://doi.org/10.1093/femspd/ftaa006

3. Patel NA. Pediatric COVID-19: systematic review of the literature. Am J Otolaryngol. 2020 Sep - Oct;41(5):102573. https://doi.org/10.1016/i.amjoto.2020.102573

4. Mallineni SK, Innes NP, Raggio DP, Araujo MP, Robertson MD, Jayaraman J. Coronavirus disease (COVID-19): characteristics in children and considerations for dentists providing their care. Int J Paediatr Dent. 2020 May;30(3):245-50. https://doi.org/10.1111/ipd.12653

5. Yang J, Zheng Y, Gou X, Pu K, Chen Z, Guo Q, et al. Prevalence of comorbidities and its effects in patients infected with SARS-CoV-2: a systematic review and meta-analysis. Int J Infect Dis. 2020 May;94:91-5. https://doi.org/10.1016/i.ijid.2020.03.017

6. Dong Y, Mo X, Hu Y, Qi X, Jiang F, Jiang Z, et al. Epidemiology of COVID-19 Among Children in China. Pediatrics. 2020 Jun;145(6):145. https://doi.org/10.1542/peds.2020-0702

7. Dasgupta K, Finch SE. A case of Pediatric Multisystem Inflammatory Syndrome temporally associated with COVID-19 in South Dakota. S D Med. 2020 Jun;73(6):246-51.

8. Jones VG, Mills M, Suarez D, Hogan CA, Yeh D, Segal JB, et al. COVID-19 and Kawasaki disease: novel virus and novel case. Hosp Pediatr. 2020 Jun;10(6):537-40. https://doi.org/10.1542/hpeds.2020-0123

9. Hong KH, Lee SW, Kim TS, Huh HJ, Lee J, Kim SY, et al. Guidelines for Laboratory Diagnosis of Coronavirus Disease 2019 (COVID-19) in Korea. Ann Lab Med. 2020 Sep;40(5):351-60. https://doi.org/10.3343/alm.2020.40.5.351

10. Granger DA, Kivlighan KT, Fortunato C, Harmon AG, Hibel LC, Schwartz EB, et al. Integration of salivary biomarkers into developmental and behaviorally-oriented research: problems and solutions for collecting specimens. Physiol Behav. 2007 Nov;92(4):583-90. https://doi.org/10.1016/i.physbeh.2007.05.004

11. Ludvigsson JF. Systematic review of COVID-19 in children shows milder cases and a better prognosis than adults. Acta Paediatr. 2020 Jun;109(6):1088-95. https://doi.org/10.1111/apa.15270

12. Yung CF, Kam KQ, Chong CY, Nadua KD, Li J, Tan NW, et al. Household transmission of Severe Acute Respiratory Syndrome Coronavirus 2 from adults to children. J Pediatr. 2020 Oct;225:249-51. https://doi.org/10.1016/i.jpeds.2020.07.009 
13. Shen KL, Yang YH, Jiang RM, Wang TY, Zhao DC, Jiang Y, et al. Updated diagnosis, treatment and prevention of COVID-19 in children: experts' consensus statement (condensed version of the second edition). World J Pediatr.2020;16:232-9. https://doi.org/10.1007/s12519-020-00362-4

14. Sankar J, Dhochak N, Kabra SK, Lodha R. COVID-19 in Children: Clinical Approach and Management. Indian J Pediatr. 2020 Jun;87(6):433-42. https://doi.org/10.1007/s12098-020-03292-1

15. Shen K, Yang Y, Wang T, Zhao D, Jiang Y, Jin R, et al. Diagnosis, treatment, and prevention of 2019 novel coronavirus infection in children: experts' consensus statement. World J Pediatr. 2020 Jun;16(3):223-31. https://doi.org/10.1007/s12519-020-00343-7

16. Credie GB, Coelho AA, Rezende KM. Coronavirus (COVID-19) in children: history and pediatric oral health. Dental Oral Biol Craniofac Res. 2020; 3(3):1-4. https://doi.org/10.31487/j.DOBCR.2020.03.06

17. Loomba RS, Villarreal E, Flores S. COVID-19 and Kawasaki syndrome: should we really be surprised? Cardiol Young. 2020 Jul;30(7):1059-60. https://doi.org/10.1017/\$1047951120001432

18. Organização das Nações Unidas para a Educação,a Ciência e a Cultura - Unicef. Recomendações para a reabertura de escolas. Apr. 2020 [cited year Month day]. Available from: https://www.unicef.org/media/68886/file/PORTUGUESE-Framework-for-reopeningschools-2020.pdf

19. Centers for Disease Control and Prevention-CDC. Preparing K-12 school administrators for a safe return to school in fall 2020.2020 [cited year Month day]. Available from:

20. Cooper DM, Guay-Woodford L, Blazar BR, Bowman S, Byington CL, Dome J, et al. Reopening Schools safely: the case for collaboration, constructive disruption of Pre-Coronavirus 2019 expectations, and creative solutions. J Pediatr. 2020 Aug;223:183-5. https://doi.org/10.1016/i.jpeds.2020.05.022

21. Viner RM, Russell SJ, Croker H, Packer J, Ward J, Stansfield C, et al. School closure and management practices during coronavirus outbreaks including COVID-19: a rapid systematic review. Lancet Child Adolesc Health. 2020 May;4(5):397-404. https://doi.org/10.1016/S2352-4642(20)30095-X

22. Walger P, Heininger U, Knuf M, Exner M, Popp W, Fischbach T, et al. Children and adolescents in the CoVid-19 pandemic: schools and daycare centers are to be opened again without restrictions. The protection of teachers, educators, carers and parents and the general hygiene rules do not conflict with this. GMS Hyg Infect Control. 2020 May;15:Docl1. https://doi.org/10.3205/dgkh000346

23. World Health Organization - WHO. Considerations for school-related public health measures in the context of COVID-19. Geneva: World Health Organization; 2020.

24. Fernandes LL, Borges L, Pacheco VB, Bernardes A, Ribeiro RR, Jimenez M, et al. SARS-CoV-2: a promising path in salivary diagnosis. Open Dent J. 2020;14(1):2. https://doi.org/10.2174/1874210602014010343

25. Cross BW, Ruhl S. Glycan recognition at the saliva - oral microbiome interface. Cell Immunol. 2018 Nov;333:19-33. https://doi.org/10.1016/j.cellimm.2018.08.008

26. Ceron JJ, Lamy E, Martinez-Subiela S, Lopez-Jornet P, Capela ESF, Eckersall PD, Tvarijonaviciute A. Use of saliva for diagnosis and monitoring the SARS-CoV-2: a general perspective. J Clin Med. 2020 May;9(5):1491. https://doi.org/10.3390/jcm9051491

27. Javaid MA, Ahmed AS, Durand R, Tran SD. Saliva as a diagnostic tool for oral and systemic diseases. J Oral Biol Craniofac Res. 2016 Jan-Apr;6(1):66-75. https://doi.org/10.1016/i.jobcr.2015.08.006

28. Pedersen AM, Sørensen CE, Proctor GB, Carpenter GH, Ekström J. Salivary secretion in health and disease. J Oral Rehabil. 2018 Sep;45(9):730-46. https://doi.org/10.1111/joor.12664

29. Zhang CZ, Cheng XQ, Li JY, Zhang P, Yi P, Xu X, et al. Saliva in the diagnosis of diseases. Int J Oral Sci. 2016 Sep;8(3):133-7. https://doi.org/10.1038/ijos.2016.38

30. Marques Filho JS, Gobara Junior J, Salomao GVS, Sumita LM, Shibli JA, Viana RG, et al. cyłokine levels and human herpesviruses in saliva from clinical periodontal healthy subjects with peri-implantitis: a case-control study. Mediators Inflamm. 2018 Aug;2018:6020625. https://doi.org/10.1155/2018/6020625

31. To KK, Chan KH, Ho J, Pang PK, Ho DT, Chang AC, et al. Respiratory virus infection among hospitalized adult patients with or without clinically apparent respiratory infection: a prospective cohort study. Clin Microbiol Infect. 2019 Dec;25(12):1539-45. https://doi.org/10.1016/i.cmi.2019.04.012

32. Castro T, Sabalza M, Barber C, Abrams W, Costa AC, Milagres FAP, et al. Rapid diagnosis of Zika virus through saliva and urine by Loopmediated isothermal amplification (LAMP). J Oral Microbiol. 2018 Sep;10(1):1510712. https://doi.org/10.1080/20002297.2018.1510712

33. Braz-Silva PH, Pallos D, Giannecchini S, To KK. SARS-CoV-2: what can saliva tell us? Oral Dis. 2020 Apr;odi.13365. https://doi.org/10.1111/odi.13365

34. To KK, Tsang OT, Yip CC, Chan KH, Wu TC, Chan JM, et al. Consistent detection of 2019 novel coronavirus in saliva. Clin Infect Dis. 2020 Jul;71(15):841-3. https://doi.org/10.1093/cid/ciaal49

35. To KK, Tsang OT, Leung WS, Tam AR, Wu TC, Lung DC, et al. Temporal profiles of viral load in posterior oropharyngeal saliva samples and serum antibody responses during infection by SARS-CoV-2: an observational cohort study. Lancet Infect Dis. 2020 May;20(5):565-74. https://doi.org/10.1016/S1473-3099(20)30196-1 
36. Long QX, Tang XJ, Shi QL, Li Q, Deng HJ, Yuan J, et al. Clinical and immunological assessment of asymptomatic SARS-CoV-2 infections. Nat Med. 2020 Aug;26(8):1200-4. https://doi.org/10.1038/s41591-020-0965-6

37. Barzon L, Pacenti M, Berto A, Sinigaglia A, Franchin E, Lavezzo E, et al. Isolation of infectious Zika virus from saliva and prolonged viral RNA shedding in a traveller returning from the Dominican Republic to Italy, January 2016. Euro Surveill. 2016;21(10):30159. https://doi.org/10.2807/1560-7917.ES.2016.21.10.30159

38. Zuanazzi D, Arts EJ, Jorge PK, Mulyar Y, Gibson R, Xiao Y, et al. Postnatal Identification of Zika Virus Peptides from Saliva. J Dent Res. 2017 Sep;96(10):1078-84. https://doi.org/10.1177/0022034517723325

39. Azzi L, Carcano G, Gianfagna F, Grossi P, Gasperina DD, Genoni A, et al. Saliva is a reliable tool to detect SARS-CoV-2. J Infect. 2020 Jul;81(1):e45-50. https://doi.org/10.1016/i.jinf.2020.04.005

40. Sabino-Silva R, Jardim AC, Siqueira WL. Coronavirus COVID-19 impacts to dentistry and potential salivary diagnosis. Clin Oral Investig. 2020 Apr;24(4):1619-21. https://doi.org/10.1007/s00784-020-03248-x

41. Klimes-Dougan B, Hastings PD, Granger DA, Usher BA, Zahn-Waxler C. Adrenocortical activity in at-risk and normally developing adolescents: individual differences in salivary cortisol basal levels, diurnal variation, and responses to social challenges. Dev Psychopathol. 2001;13(3):695-719. https://doi.org/10.1017/S0954579401003157

42. Navazesh M. Saliva in health and disease. J Calif Dent Assoc. 2011 Sep;39(9):626-8.

43. Hanrahan K, McCarthy AM, Kleiber C, Lutgendorf S, Tsalikian E. Strategies for salivary cortisol collection and analysis in research with children. Appl Nurs Res. 2006 May;19(2):95-101. https://doi.org/10.1016/i.apnr.2006.02.001

44. Herrington CJ, Olomu IN, Geller SM. Salivary cortisol as indicators of pain in preterm infants: a pilot study. Clin Nurs Res. 2004 Feb;13(1):53-68. https://doi.org/10.1177/1054773803259665

45. Walker RF, Riad-Fahmy D, Read GF. Adrenal status assessed by direct radioimmunoassay of cortisol in whole saliva or parotid saliva. Clin Chem. 1978 Sep;24(9):1460-3. https://doi.org/10.1093/clinchem/24.9.1460

46. Klug I, Dressendörfer R, Strasburger C, Kühl GP, Reiter HL, Reich A, et al. Cortisol and 17-hydroxyprogesterone levels in saliva of healthy neonates: normative data and relation to body mass index, arterial cord blood ph and time of sampling after birth. Biol Neonate. 2000 Jul;78(1):22-6. https://doi.org/10.1159/000014242

47. Jones JM, Watkins CA, Hand JS, Warren JJ, Cowen HJ. Comparison of three salivary flow rate assessment methods in an elderly population. Community Dent Oral Epidemiol. 2000 Jun;28(3):177-84. https://doi.org/10.1034/j.1600-0528.2000.280303.x

48. Strazdins L, Meyerkort S, Brent V, D'Souza RM, Broom DH, Kyd JM. Impact of saliva collection methods on slgA and cortisol assays and acceptability to participants. J Immunol Methods. 2005 Dec;307(1-2):167-71. https://doi.org/10.1016/i.jim.2005.09.010

49. Navazesh M, Mulligan RA, Kipnis V, Denny PA, Denny PC. Comparison of whole saliva flow rates and mucin concentrations in healthy Caucasian young and aged adults. J Dent Res. 1992 Jun;71(6):1275-8. https://doi.org/10.1177/00220345920710060201

50. Sapkota D, Søland TM, Galtung HK, Sand LP, Giannecchini S, To KKW, et al. COVID-19 salivary signature: diagnostic and research opportunities. J Clin Pathol. 2020;0:1-6. https://doi.org/10.1136/jclinpath-2020-206834 